\title{
Correcting for Salivary Contamination of Esophageal Fistula Samples
}

\author{
RICHARD H. HART
}

\begin{abstract}
The effect of salivary contamination on composition of esophageal ejecta samples can be calculated easily. Such calculations indicate contamination has little effect on the concentration of any organic constituent. Rinsing ejecta samples in distilled water should be discontinued because it reduces crude protein concentration and in vitro dry matter digestibility and increases acid detergent fiber and lignin concentration.
\end{abstract}

Esophageal-fistulated animals are routinely used to sample diets of grazing animals. However, researchers disagree about the extent to which chemical composition of the diet sample is changed by salivary contamination. Wallace et al. (1972) reviewed 9 studies which compared composition of diets with that of esophageal fistula samples of the same diets. Two of the 9 studies reported less nitrogen in the sample than in the diet, and 2 reported the sample was less digestible than the diet. All reported a higher ash content in the sample. Wallace et al. (1972) found no differences in composition of diets and fistula samples, or in samples of untreated forage and forage soaked in saliva, when results were reported on an organic matter basis. Kiesling et al. (1969) stated: "Except for ash, the differences in chemical composition between hand-plucked and esophageal-fistula samples (are) apparently due to selectivity by the grazing steers."

Direct comparisons of diets and ejecta samples are plagued by extraneous sources of variance in sample collection, preparation, and analysis. Such variance can be avoided by approaching the problem mathematically. We can determine $D_{s}, D_{f}$ and $D_{e}$, the dry matter concentrations in saliva, forage and ejecta, respectively. The dry matter concentration of ejecta is equal to the proportion of saliva in the sample times the dry matter concentration of saliva, plus the proportion of forage in the sample times the dry matter concentration of forage, or, if $S$ and $F$ are the proportions of the ejecta contributed by saliva and forage,

$\begin{array}{lc}\text { Because } & S D_{\mathrm{g}}+F D_{\mathrm{f}}=\mathrm{D}_{\mathrm{e}} . \\ \text {, then } & \mathrm{F}=1-\mathrm{S} \\ , & \mathrm{SD}_{\mathrm{a}}+(1-S) \mathrm{D}_{\mathrm{f}}=\mathrm{D}_{\mathrm{e}} \\ \text {, ind } & \mathrm{SD}_{\mathrm{a}}+\mathrm{D}_{\mathrm{f}}-\mathrm{SD}_{\mathrm{f}}=\mathrm{D}_{\mathrm{e}} \\ \text { and } & S\left(D_{\mathrm{s}}-\mathrm{D}_{\mathrm{f}}\right)=\mathrm{D}_{\mathrm{e}}-\mathrm{D}_{\mathrm{f}} \\ & \mathrm{S}=\left(\mathrm{D}_{\mathrm{e}}-\mathrm{D}_{\mathrm{f}}\right) /\left(\mathrm{D}_{\mathrm{g}}-\mathrm{D}_{\mathrm{f}}\right) .\end{array}$

The proportion of the dry matter in the ejecta contributed by saliva is equal to the proportion of saliva in the sample times the dry matter concentration of saliva, divided by the dry matter concentration of the ejecta, or $\quad \mathrm{S}_{\mathrm{d}}=\mathrm{SD}_{\mathrm{s}} / \mathrm{D}_{\mathrm{e}}$.

$$
\text { Substituting equation (6), } \quad S_{d}=\frac{D_{s}\left(D_{e}-D_{f}\right)}{D_{e}\left(D_{s}-D_{f}\right)}
$$

Then the proportion of the dry matter in the ejecta contributed by forage,

$$
F_{d}=1-S_{d} \text {. }
$$

Then if $C_{e}, C_{t}$ and $C_{f}$ are the concentrations of any constituent in the dry matter of ejecta, saliva and forage, respectively.

$$
\mathrm{C}_{\mathrm{e}}=\mathrm{C}_{\mathrm{s}} \mathrm{S}_{\mathrm{d}}+\mathrm{C}_{\mathrm{f}} \mathrm{F}_{\mathrm{d}}
$$

Author is research agronomist, USDA, Agricultural Research Service, High Plains Grasslands Research Station, 8408 Hildreth Road, Cheyenne, Wyo. 82009.
, and $\quad \mathrm{C}_{\mathrm{t}}=\left(\mathrm{C}_{\mathrm{e}}-\mathrm{C}_{\mathrm{s}} \mathrm{S}_{\mathrm{d}}\right) / \mathrm{F}_{\mathrm{d}}$.

Marshall, et al. (1967) found $0.9 \%$ dry matter in bovine saliva and reported the composition of saliva dry matter (Table I). Hart et al. (1983) noted dry matter concentrations of 50 and $23 \%$ in range forage and ejecta, respectively, when samples of each were collected simultaneously. Using these figures, the composition of an ejecta sample derived from a typical forage sample was calculated. First $S_{d}$, the proportion of the ejecta dry matter contributed by saliva, was calculated, using equation (8), as

$$
\mathrm{S}_{d}=\frac{.009(.23-.50)}{.23(.009-.50)}=.0215
$$

Then the proportion of ejecta dry matter contributed by forage, using equation (9), is

$$
F_{d}=1-.0215=.9785 \text {. }
$$

With such a small proportion of the dry matter in the ejecta contributed by saliva, it is obvious that the composition of the ejecta will be very similar to that of the forage except for those constituents present in grossly different proportions in saliva and forage. Equation (10) was used to calculate ejecta composition from the values of $S_{d}$ and $F_{d}$ computed above and saliva and forage composition as given in Table 1 . For example, if $C_{e}$ is nitrogen content of ejecta, we calculate it as

$$
\begin{aligned}
\mathrm{C}_{\mathrm{e}} & =1.33(.0215)+1.92(.9785) \\
& =1.907
\end{aligned}
$$

Except in the case of ash, any differences in composition between forage and ejecta are quite small (Table 1) and probably within the limits of experimental error. Lesperance et al. (1974) gave slightly different figures for salivary composition, namely $1.06 \%$ dry matter, $80 \%$ ash on a dry matter basis, and $0.1-1.2 \%$ nitrogen, with most samples in the $0.1-0.2 \%$ range, on a wet basis. This range in salivary composition would not alter the conclusions that salivary contamination has a minimal effect on all constituents of esophageal ejecta with the exception of ash. Furthermore, the composition of saliva can be determined and the dry matter content of the

Table 1. Composition of hovine saliva (Marshall, et. al. 1967) and a typical forage sample, and calculated composition of the derived esophageal ejecta sample.

\begin{tabular}{lccc}
\hline \hline Component & Saliva & Forage & Ejecta \\
\hline & \multicolumn{4}{c}{$\%$, wet basis } \\
\cline { 2 - 4 } Dry matter & 0.9 & 50.0 & 23.0 \\
& \multicolumn{3}{c}{$\%$, dry matter basis } \\
\cline { 2 - 4 } Nitrogen & 1.33 & 1.92 & 1.91 \\
Crude protein & 8.3 & 12.0 & 11.9 \\
Neutral detergent fiber & 0.0 & 68.0 & 66.5 \\
Acid detergent fiber & 0.0 & 38.0 & 37.2 \\
Lignin & 0.0 & 6.5 & 6.4 \\
Ash & 95.6 & 8.0 & 9.9 \\
ln vitro dry matter & & & 62.0 \\
\multicolumn{1}{l}{ digestibility } & 100.0 & 62.0 & 6 \\
\hline
\end{tabular}


forage estimated with some accuracy so that the equations given can be used to adjust composition of samples for contamination.

Some researchers have sought to minimize contamination by squeezing the ejecta sample lightly to remove excess saliva, while others recommend rinsing with distilled water. When the quality of cattle diets was studied at Cheyenne (Hart et al. 1983), initially some of the student researchers rinsed and some squeezed the ejecta samples. We noted that rinsed samples were consistently lower in crude protein and in vitro dry matter digestibility (IVDMD) and usually higher in fiber components than were squeezed samples. Therefore, in 1977 we divided each ejecta sample and squeezed half and rinsed half of each. The rinsed subsamples averaged 1.1 percentage points less crude protein, 2.0 percentage points more acid detergent fiber, 0.5 percentage points more lignin, and 5.7 percentage points lower in IVDMD. These differences were highly significant and quite consistent throughout the season. There was no significant difference in neutral detergent fiber between the two methods of sample preparation. Because of these findings we no longer rinse esophageal ejecta samples, and have discarded any data based on rinsed samples.

\section{Literature Cited}

Hart, R.H., O.M. Abdalla, D.H. Clark, M.B. Marshall, M.H. Hamid. J.A. Hager, and J.W. Waggoner, Jr. 1983. Quality of forage and cattle diets on the Wyoming High Plains. J. Range Manage. 37:46-51.

Kiesling, H.E., A.B. Nelson, and C.H. Herbel. 1969. Chemical composition of tobosa grass collected by hand-plucking and esophageal fistulated steers. J. Range Manage. 22:155-159.

Lesperance, A.L., D.C. Clanton, A.B. Nelson, and C.B. Theurer. 1974. Factors affecting the apparent chemical composition of fistula samples. Nevada Agr. Exp. Sta. Pub. T18.

Marshall, B., D.T. Torell and R.M. Bredon. 1967. Comparison of tropical forages of known composition with samples of these forages collected by esophageal fistulated animals. J. Range Manage. 20:210-313.

Wallace, J.D., D.N. Hyder, and G.M. Van Dyne. 1972. Salivary contamination of forage selected by esophageal fistulated steers grazing sandhill grassland. J. Range manage. 25:184-187.

\title{
1983 SRM Summer Meeting July 17-21, 1983
}

\author{
University of Southern Mississippi \\ Gulf Coast Regional Campus \\ Long Beach, MS (2 miles west of Gulfport) \\ More information will be in the April 1983 Rangelands
}

